Journal of Atmospheric and Oceanic Technology

$3(1) .1986$, S. $75-83$

\title{
A Low-Cost Digital XBT System and its Application to the Real-Time Computation of Dynamic Height
}

\author{
W. J. EMERY,* W. LEE, ${ }^{* *}$ W. ZENK ${ }^{\oplus}$ AND J. MEINCKE ${ }^{\ddagger}$ \\ *Department of Oceanography, University of British Columbia, Vancouver, B.C., V6T IW5, Canada \\ **Institute of Marine Science, University of Alaska, Fairbanks, $A L$ \\ ${ }^{-}$Institut für Meereskunde, 2300 Kiel 1, West Germany \\ ${ }^{\ddagger}$ Institut für Meereskunde, 2000 Hamburg 13, West Germany
}

(Manuscript received 8 April 1985, in final form 23 July 1985)

\begin{abstract}
An XBT interface is described for use with Commodore and other 6502 based microprocessors. This interface takes the form of a single circuit board mounted inside the microcomputer and is completely software controlled. The application of this digital XBT system to the real-time computation of density and dynamic heights, using historical or recent temperature-salinity relationships, is also described. Comparison between XBT and CTD measured temperatures from the Northeast Atlantic yield a mean temperature difference of $-0.08^{\circ} \mathrm{C}$ and an $\mathrm{rms}$ temperature difference of $0.33^{\circ} \mathrm{C}$ for the upper $800 \mathrm{~m}$. Examples of dynamic topography maps and a temperature section computed using this technique are also presented and comparison between objectively analyzed XBT and CTD dynamic topographies demonstrates the reliability of the method for mapping the baroclinic flow.
\end{abstract}

\section{Introduction}

The expendable bathythermograph (XBT) is becoming an increasingly important measurement tool in oceanography. It boasts the advantage that data may be collected rapidly while the ship is underway reducing the time to survey an area and yielding a much more synoptic picture of the ocean. Also the simplicity of the system means that it does not require sophisticated support equipment and data may be collected from a variety of ship types. Thus merchant "ships-of-opportunity" are now being widely used as XBT platforms to collect thermal structure data along well-traveled shipping routes.

For many years XBT data were recorded on analog strip charts which were subsequently digitized by hand. Recently the availability of microprocessor systems has made it possible to record the XBT data digitally on either tape or floppy disk and to compute real time derived quantities from these XBT temperature data. A distinct advantage of the digital systems is that they are not subject to the mechanical errors inherent in the analog recorders. Thus the digital systems don't require repeated mechanical calibration to define the error limits of the instrument. As evidence of the magnitude of the errors connected with the use of a variety of analog recorders, XBT data from a series of seven Atlantic research cruises were compared. Different recorders were used on these cruises and no special effort was made to intercalibrate the systems. The mean temperature difference between $191 \mathrm{XBT}$ and coincident CTD temperatures was $0.15^{\circ} \mathrm{C}$ with a standard deviation of $0.23^{\circ} \mathrm{C}$ for all seven cruises. This is comparable to the mean temperature difference of $0.13^{\circ} \mathrm{C}$ and a standard deviation of $0.11^{\circ} \mathrm{C}$ given for $\mathrm{T} 7(800$ $\mathrm{m})$ probes using a wide variety of analog XBT systems as reported by Heinmiller et al. (1983).

Another advantage of digital XBT systems is that no subsequent digitization of the analog traces is required to put the data into computer compatible form. This aspect of the analog XBT system was often the source of subtle errors introduced by the laborious hand digitizing of the analog traces. Thus the new digital systems save both in terms of manpower and avoiding errors as well as providing the capability for the realtime computation of derived quantities such as dynamic height (geopotential anomaly).

The recent expansion of XBT use in scientific programs, both from research vessels and ships-of-opportunity, requires the availability of computational capabilities to compute derived quantities in quasi-realtime. This paper describes such a system based on a 6502 based microprocessor. Specifically a procedure developed for estimating dynamic height will be described and results obtained with this system will be compared with reference data taken using more accurate CTD profiling systems. Examples of dynamic height maps and a section produced using such a system 
will be presented. It is hoped that this description will stimulate other interested investigators to also build such a system for their own applications.

\section{Other digital XBT systems}

The microprocessor based XBT system discussed in this paper is not a particularly new development and similar systems have existed for quite a while. These digital systems range from the complex interface systems offered by commercial firms such as Sippican and Bathysystems to a simple digitization of the signal from a standard Sippican analog recorder (John Dugan, personal communication, 1985). A forerunner of the system described in this paper was developed at Oregon State University (OSU; Mesecar and Wagner, 1980). It was based on a Commodore microcomputer and was designed to simplify the preparation of radio "bathymessages" being sent from ships of opportunity. With the analog systems ship operators visually read off temperature-depth pairs which were sent by radio to shore. The microcomputer digital system produces direct values which save reading the analog traces. The system discussed by 'Mesecar and Wagner included an algorithm to automatically compose the bathy-message to be sent by radio.

More complex digital XBT recording systems are presently available from both Sippican and Bathysystems. These systems also use a microcomputer (HP85 ) for data reduction and recording. The main advantage of these systems is that they are general data logging devices and can be used with a variety of other expendable profilers with the appropriate software.

The primary advantage of the system discussed below is its relative low-cost of production. Like the OSU system, it uses a Commodore microcomputer (or possibly any other 6502 based microcomputer) which is significantly less expensive than the HP-85. The XBT interface itself is inexpensive to assemble. The Commodore system has computational power and flexibility similar to that of the HP-85 and its low cost allows one to add a disk drive with SBT data recording on floppydisk rather than on cassette tape. Rapid access to the data on disk is needed for the quasi-real-time computation of derived quantities such as dynamic topography: Access to these derived quantities in near realtime was the purpose for developing this system and adds greatly to the ability to evaluate shipboard sampling programs while still in the field. Parameters such as density, dynamic height and sound velocity can be easily calculated by the system.

\section{XBT interface}

The central feature of our XBT system is the interface between the launcher and the microcomputer. The interface is built as a single circuit board which is mounted internal to the computer and is controlled strictly through software commands from the computer. This eliminates any physical contact through buttons or switches which can be accidently switched or may become mechanically defective. It also makes the conversion of the microcomputer to an XBT system almost physically transparent.

The only external evidence is the terminal block where the launcher cable leads are attached to the computer. Another advantage of this interface is that the internally mounted circuit board uses the same power supply as the microcomputer itself. Thus no added power source is needed for the interface.

The interface acts to convert the resistance value of the probe-thermistor to a digital temperature value. The primary component of this interface is an Intersic ICL 7109 12-bit binary A/D converter. On the interface board, shown as a block diagram in Fig. 1, (a more complete description of this interface can be found in Zenk et al., 1985), there are two sources of constant electrical current which give rise to voltage differences with the sea water itself and with the sea water through a thermistor connected in series. The voltage difference between points $A$ and $C$ is proportional to the resistance of the thermistor and is the system signal fed into the differential amplifiers. Here the voltage signal difference is increased before being sent to the $\mathrm{A} / \mathrm{D}$ converter. The A/D converter translates the measured voltage difference, from the amplifiers, into a 12-bit digital word. The computer receives this information, plus additional status bits, in two parallel 8-bit words (first the high byte and then the low byte). From these 2 bytes the computer calculates the corresponding resistance loaded as a floating point quantity.

The interface senses the presence of a probe canister in the launcher when the circuit is closed, by the probe connection, and current flows through point $B$ to connect with the signal driver. This value is constantly interrogated by the microprocessor for the presence of current after which it activates the trigger relay. The entry of the probe into sea water is sensed by the change in the resistance of the thermistor when it contacts the sea surface. For the software in use the limit is set at 700 ohms above which the probe is taken to be in sea water. The end of a cast is also sensed by the change in resistance of the thermistor which when below 700 ohms is considered to no longer be connected. If this occurs before the expected depth value the software reports that the copper wire is prematurely broken.

In the configuration shown in Fig. 1 this interface board connects directly to a 6502 based microprocessor. Thus the interface depends not only on the microprocessor for its power supply but also delivers a signal directly to the host computer. This interface can be modified (as described in Zenk et al., 1985) to produce a serial output (RS232C or other) which could then be fed into a serial port on any computer system. This generalization makes the interface compatible 


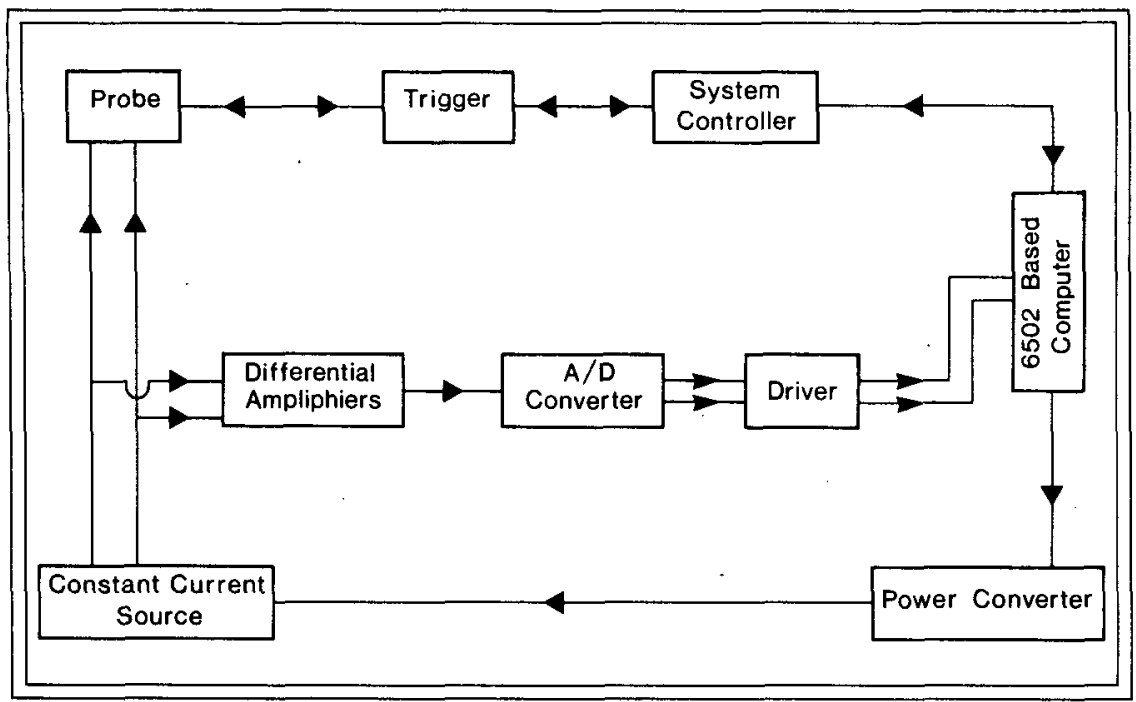

FiG. 1. Block diagram of XBT interface board for the Commodore 8032 Microcomputer.

with a wide variety of computers and makes the transition to 16-bit machines simple.

\section{Calibrating the XBT interface}

Both installation and calibration of the XBT interface were simplified with a system test unit. This "test box" consisted of a set of resistances that could be selected by a switch or a variable resistor. The calibration temperatures for the resistances used are given in Table 1. The calibration procedure consists of setting the A/D reference voltage, balancing the current sources and setting the differential amplifier gains. To balance the current sources the "test box" is connected to points A, B and C (Fig. 1) in place of the XBT probe. The "test box" is then used to balance the currents in branches $\mathrm{A}$ and $\mathrm{C}$. A similar procedure is used to equalize the effects of the two differential amplifiers. This procedure is described more fully in Zenk et al. (1985).

TABLE 1. Correspondence between resistance and temperature.

\begin{tabular}{cc}
\hline \hline $\begin{array}{c}\text { Resistance } \\
\text { (ohms) }\end{array}$ & $\begin{array}{c}\text { Temperature } \\
\left({ }^{\circ} \mathrm{C}\right)\end{array}$ \\
\hline 17500 & -1.35 \\
15000 & 1.67 \\
12500 & 5.32 \\
10000 & 9.90 \\
7145 & 17.06 \\
6153 & 20.34 \\
5000 & 25.01 \\
4166 & 29.22 \\
3750 & 31.71 \\
3334 & 34.52 \\
\hline
\end{tabular}

Now that the system has been set up, the "test box" can be used, in conjunction with a test program, to determine if the XBT system is operating or not and to check the temperature settings at various set resistance values. A flow chart of the test program is given in Fig. 2. With the test program loaded and running the "test box" can be used to test the system for its response to a probe being loaded into the launcher and launched. With the probe in launched mode the "test box" can be used to either generate the fixed resistances given in Table 1 or a variable resistor can be employed to cover the entire resistance/temperature range in question. The fixed resistances, however, are used to compute the coefficients of a quadratic fit between the measured digital values and resistance. For this reason 10 resistance values (Table 1) are used which cover the entire range of temperatures. Since each $A / D$ converter behaves slightly differently this calibration procedure must be carried out for each XBT interface. From these values corresponding to Table 1 a quadratic leastsquares fit is made between the recorded digital values and the matching resistances. The resulting three coefficients $A_{0}, A_{1}$, and $A_{2}$ are then used in the XBT data collection software to convert the measured digital values into resistances which are then converted to temperature. After the digital values have been listed for the "test box" resistances the test program can be terminated.

\section{Temperature-depth computation}

In order to convert the resistance values to temperature a logarithmic formula was used following the results of Steinhart and Hart (1968) that demonstrated 
Calibration Test Program

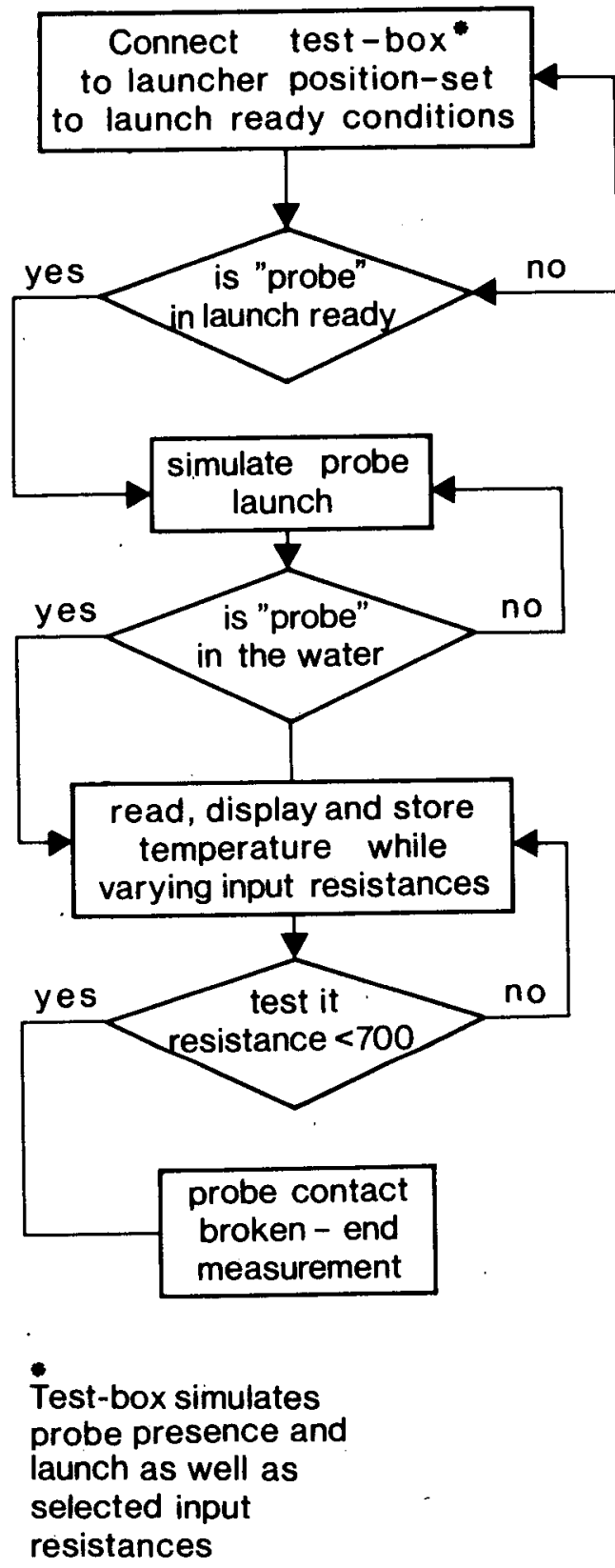

FIG. 2. Flow chart of test program.

the accuracy of such a logarithmic fit for a thermistor. The formula is

$$
\begin{array}{r}
T=\left[1.34079 \times 10^{-3}+\ln (R) \times\left(2.1604 \times 10^{-1}\right.\right. \\
\left.\left.+\ln (R) \times 2.38522 \times 10^{-6}\right)^{-1}\right]-273.15
\end{array}
$$

where $T$ is temperature in ${ }^{\circ} \mathrm{C}$ and $R$ is resistance in ohms. (This formula is less accurate for Arctic tem- perature ranges as is discussed by Joyce et al., 1976). With the 12-bit A/D conversion this system has a temperature resolution better than $0.01^{\circ} \mathrm{C}$. With proper calibration this digital system should not contribute added inaccuracy to this temperature measurement. Thus the overall temperature accuracy depends on the consistency of the individual thermistors in the XBT probes. While Sippican publishes a value of $\pm 0.2^{\circ} \mathrm{C}$ statistics from samples of thermistor batches (Emery, 1978) have shown a precision of $\pm 0.06^{\circ} \mathrm{C}$.

The depth calculation follows the formula given by Sippican (1970)

$$
D=6.472 t-0.00216 t^{2}
$$

where $D$ is the depth in $\mathrm{m}$ and $t$ is the elapsed time in seconds. No effort has been made to correct for some of the fall rate errors described in Heinmiller et al. (1983).

\section{Temperature comparison}

To evaluate the accuracy of data from this digital XBT system, relative to CTD data, a series of 41 XBT profiles were collected midway between 42 CTD casts each separated by $15 \mathrm{~km}$. These data were all collected in July 1984 in the Northeast Atlantic west of the Rockall Channel. The temperature comparison was performed by taking the depth of each one degree Celsius isotherm, from the microcomputer printout of the XBT data and relating it to the temperature read at that depth from the adjacent CTD listings. The generally most similar neighboring CTD temperature profile was selected for the statistical comparison with the XBT profile in an effort to minimize the effects of spatial variability.

Depending on the mean observed vertical temperature range this procedure resulted in temperature differences being calculated for a maximum of 10 levels within the nominal $800 \mathrm{~m}$ depth of the "deep blue" (T7) XBT probes being used. This procedure yielded a different number of isotherm comparisons per depth level depending on the local vertical temperature gradient (Fig. 3, Table 2). This approach was considered favorable, however, in that it minimizes the effects of spatial variability on the statistical comparison.

Overall the values of $0.08^{\circ} \mathrm{C}$ for the mean temperature difference and $0.33^{\circ} \mathrm{C}$ for the rms difference are quite small; this is particularly true if we consider that the profiles, used in this comparison, were not taken simultaneously. Thus the mean and rms differences represent maximum values and similar truly simultaneous comparisons should have yielded even smaller differences. Unfortunately no such set of simultaneous XBT/CTD measurements, using this digital XBT system, was available. The fact that the mean difference for this comparison $\left(0.08^{\circ} \mathrm{C}\right)$ was smaller than the 0.1 

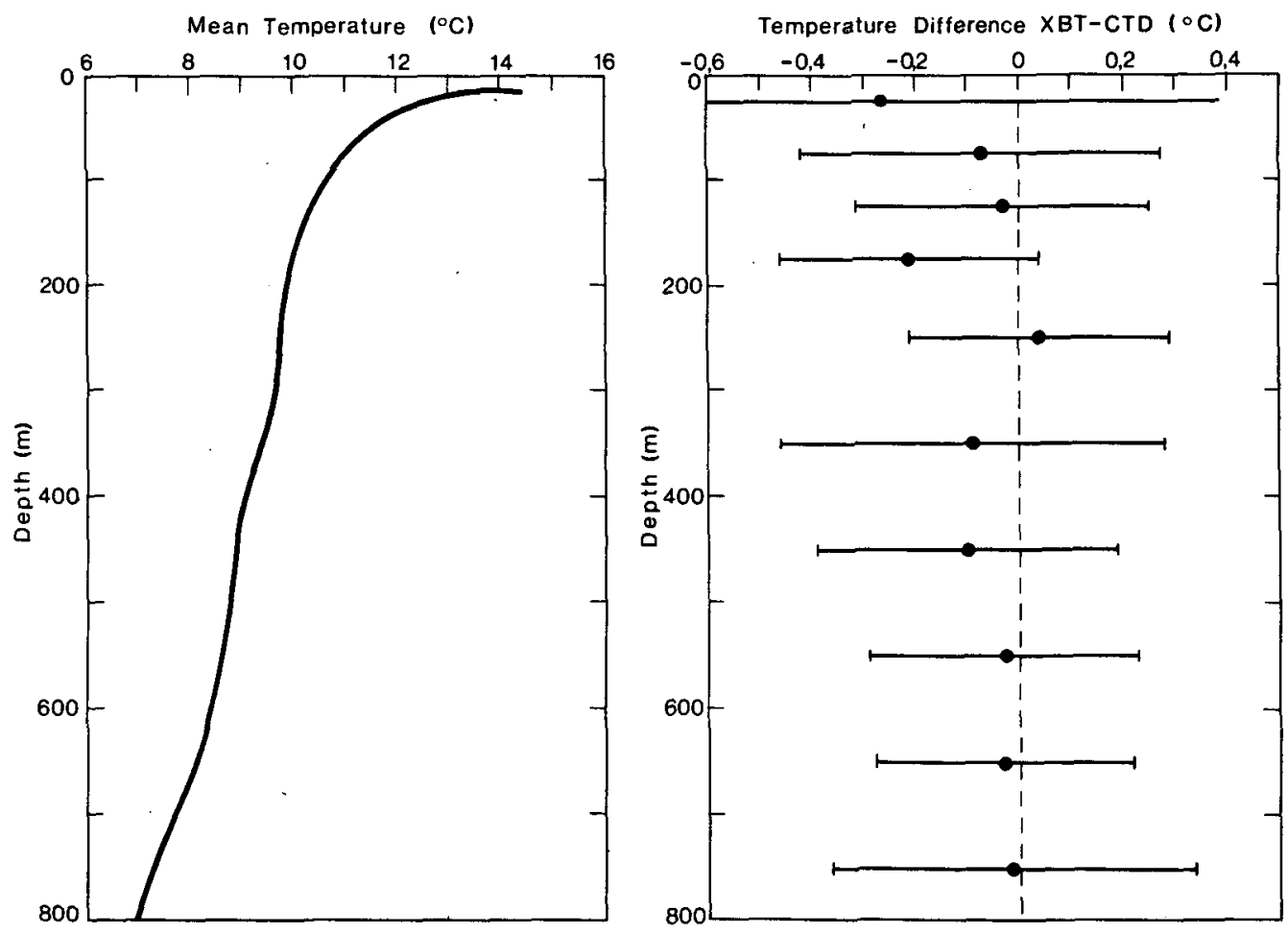

FIG. 3. Mean temperature profile (left) for the set of XBT-CTD comparison data; (right) mean temperature difference and standard deviation between XBT and CTD profiles.

to $0.13^{\circ} \mathrm{C}$ given by Heinmiller et al. (1983), and also smaller than the $0.15^{\circ} \mathrm{C}$ difference given earlier for simultaneous comparisons between CTD temperatures and XBT profiles from analog recorders, suggests that the digital system provides some improvement in the quality of the observations. The somewhat higher rms difference of $0.33^{\circ} \mathrm{C}$, as compared to Heinmiller et al.'s value of $0.18^{\circ} \mathrm{C}$ and even the $0.23^{\circ} \mathrm{C}$ for the earlier analog data comparison, is likely due to the spatial variations of the thermal structure inherent in the

TABLE 2. Comparison between $41 \mathrm{XBT}$ and CTD casts from Poseidon $I I I$ in the area west of the Rockall Channel $\left(54^{\circ} \mathrm{N}, 18^{\circ} \mathrm{W}\right)$.

\begin{tabular}{ccc}
$\begin{array}{c}\text { Depth } \\
(\mathrm{m})\end{array}$ & $\begin{array}{c}\text { Mean temperature } \\
\text { difference } \\
\left({ }^{\circ} \mathrm{C}\right)\end{array}$ & $\begin{array}{c}\text { Temperature difference } \\
\text { standard deviation } \\
\left({ }^{\circ} \mathrm{C}\right)\end{array}$ \\
\hline 25 & -0.26 & 0.64 \\
75 & -0.07 & 0.35 \\
125 & -0.03 & 0.28 \\
175 & -0.21 & 0.25 \\
250 & 0.04 & 0.25 \\
350 & -0.09 & 0.37 \\
450 & -0.10 & 0.29 \\
550 & -0.03 & 0.26 \\
650 & -0.03 & 0.25 \\
750 & -0.01 & 0.35 \\
\hline
\end{tabular}

present comparison data. Future, more simultaneous comparisons, will hopefully confirm improvement even in terms of the rms differences.

\section{Inferring salinity}

Since the XBT system measures only the vertical temperature profile it is necessary to supply added salinity information in order to calculate quantities such as density and dynamic height (geopotential anomaly). In many regions of the ocean it is possible to infer salinity from mean or ideal temperature-salinity $(T-S)$ relationships (Emery and Dewar, 1982; Siedler and Stramma, 1983; Flierl, 1978; Zantopp and Leaman, 1984). In higher latitudes of the North Pacific, Emery and O'Brien (1978) demonstrated that $T-S$ relationships did not lead to meaningful dynamic height values but instead mean salinity profiles $(S-Z)$ could be used to infer salinity from depth. A similar analysis for the North Atlantic is given in Emery and Dewar (1982). Thus software was developed to use historical mean $T-S$ and $S-Z$ curves to infer salinity primarily for the computation of dynamic height. In order to compare with locally observed $T-S$ relationships an option was built into the program to enter a newly observed $T-S$ curve (say from a nearby CTD cast) for the salinity inference. It should be noted here that it 
would be a simple extension to compute sound velocity in this same program.

\section{Computation of dynamic height}

The traditional definition of the dynamic depth anomaly is the integral of specific volume over a pressure interval. As discussed by Montgomery and Wooster (1954) this procedure is favored over that of integrating density over geopotential since it allows one to operate with a specific depth interval. These authors also argue that the pressure corrections to specific volume can be neglected in the upper $1000 \mathrm{~m}$ and thus introduce a specific volume anomaly with the pressure terms omitted, called the thermosteric anomaly. Nevertheless most oceanographers still use the more cumbersome formulation and either include all of the specific volume terms or use a modern equation of state to compute all of these specific volumes. At the same time the computer routines generally compute sigma$t$ to represent density. It would be computationally economical if a method were developed to compute geopotential anomaly directly from sigma- $t$ without the computation of specific volume anomalies. Such a calculation would only be valid for the upper layer $(\leqslant 1000$ $\mathrm{m}$ ) which includes the maximum depth of the $\mathrm{T} 7$ (or deep blue) XBT probe $(\leqslant 800 \mathrm{~m})$.

The derivation of such a formula is very straightforward and follows from the definition of dynamic depth. Using sigma- $t\left(\sigma_{t}\right)$ as a pressure independent density value the formula for the dynamic depth anomaly is

$$
\Delta D=\frac{g}{1028}\left[\left(z_{2}-z_{1}\right) \times 28.13-\int_{z_{1}}^{z_{2}} \sigma_{t} d z\right]
$$

where $g$ is the acceleration of gravity (in $\mathrm{cm} \mathrm{s}^{-2}$ ) and the depth $z$ is in $\mathrm{m}$. The dynamic depth anomaly $(\Delta D)$, in this equation, is in units of $\mathrm{m}^{2} \mathrm{~s}^{-2}$ and must be divided by 10 to get the traditional unit of dynamic meters.

As a test of the accuracy of this equation a sample calculation was carried out using data from a table in Sverdrup et al. (1942). Values of temperature, salinity, sigma- $t$ and dynamic depth anomaly $\left(\Delta D_{\mathrm{Sv}}\right)$, taken from this example are in Table 3 . Also included in this table are the dynamic depths computed using Eq. (3) $\left(\Delta D_{d}\right)$, along with the differences between $\Delta D_{S v}$ and $\Delta D_{d}$. As expected, the difference between these two dynamic depths increases with depth as the neglected pressure terms become more important. Down to 500 $\mathrm{m}$, however, the difference is only $1.4 \mathrm{dyn} \mathrm{cm}$. Since spatial differences of the dynamic height values are of most interest, and errors can be expected to cancel, this error level was considered tolerable and dynamic height was routinely computed with this equation in the XBT system software. There is a considerable computational savings in using this method which is

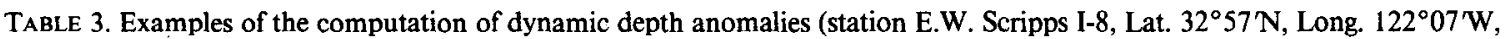
February 17, 1938, see Sverdrup et al., 1942, Table 61).

\begin{tabular}{|c|c|c|c|c|c|c|}
\hline $\begin{array}{c}\text { Depth } \\
\text { (m) }\end{array}$ & $\begin{array}{c}\text { Temp. } \\
\left({ }^{\circ} \mathrm{C}\right)\end{array}$ & $\begin{array}{c}\text { Salinity } \\
(\% 0)\end{array}$ & $\sigma_{t}$ & $\begin{array}{c}\Delta D_{\mathrm{sv}} \\
\left(\text { dyn m}^{-1}\right)\end{array}$ & $\begin{array}{c}\Delta D_{d}^{\ddagger} \\
\left(\text { dyn } \mathrm{m}^{-1}\right)\end{array}$ & Difference* \\
\hline 0 & 14.22 & 33.25 & 24.81 & & & \\
\hline 10 & 13.72 & 0.24 & 0.91 & 0.310 & 0.0311 & -0.0001 \\
\hline 25 & 0.71 & 0.24 & 0.91 & 0.0769 & 0.0772 & -0.0003 \\
\hline 50 & 0.35 & 0.30 & 25.03 & 0.1521 & 0.1525 & -0.0004 \\
\hline 75 & 9.96 & 0.57 & 0.86 & 0.2162 & 0.2165 & -0.0003 \\
\hline 100 & 0.38 & 0.84 & 26.17 & 0.2667 & 0.2668 & -0.0001 \\
\hline 150 & 8.82 & 0.98 & 0.37 & 0.3557 & 0.3555 & 0.0002 \\
\hline 200 & 0.48 & 34.09 & 0.51 & 0.4372 & 0.4361 & 0.0011 \\
\hline 250 & 0.30 & 0.16 & 0.59 & 0.5140 & 0.5114 & 0.0026 \\
\hline 300 & 7.87 & 0.20 & 0.69 & 0.5868 & 0.5824 & 0.0044 \\
\hline 400 & 0.07 & 0.20 & 0.80 & 0.7233 & 0.7144 & 0.0089 \\
\hline 500 & 6.14 & 0.26 & 0.97 & 0.8473 & 0.8331 & 0.0142 \\
\hline 600 & 5.51 & 0.35 & 27.12 & 0.9568 & 0.9365 & 0.0203 \\
\hline 800 & 4.65 & 0.42 & 0.28 & 1.1478 & 1.1138 & 0.0340 \\
\hline 1000 & 3.99 & 0.44 & 0.36 & 1.3178 & 1.2682 & 0.0496 \\
\hline 1200 & 0.52 & 0.52 & 0.48 & 1.470 & 1.4035 & 0.0665 \\
\hline 1400 & 0.07 & 0.54 & 0.54 & 1.606 & 1.5218 & 0.0842 \\
\hline 1600 & 2.69 & 0.56 & 0.59 & 1.733 & 1.6295 & 0.1035 \\
\hline 1800 & 0.37 & 0.59 & 0.64 & 1.850 & 1.7276 & 0.1224 \\
\hline 2000 & 0.13 & 0.64 & 0.69 & 1.957 & 1.8163 & 0.1407 \\
\hline 3000 & 1.62 & 0.63 & 0.76 & 2.437 & 2.2023 & 0.2347 \\
\hline 4000 & 0.50 & 0.70 & 0.81 & 2.877 & 2.5312 & 0.3458 \\
\hline
\end{tabular}

$\Delta D_{\mathrm{Sv}}$ is calculated using the specific volume anomaly (Sverdrup et al., 1942, p. 409).

${ }^{*} \Delta D_{d}$ is calculated from Eq. (3).

* Difference is $\Delta D_{\mathrm{Sv}}-\Delta D_{d}$. 
important when working with relatively slow microcomputers.

\section{Examples of derived quantities}

As an example of the data produced by such a system an XBT temperature section between Lisbon, Portugal and the Azores is shown in Fig. 4 along with the corresponding horizontal profile of $0 / 500 \mathrm{db}$ dynamic height. In this region the $T-S$ relationship is fairly tight (Siedler and Stramma, 1983; Emery and Dewar, 1982) and can be reliably used to infer salinity for density and dynamic height calculations. The dynamic height in Fig. 4 together with the characteristic slopes of the $15^{\circ} \mathrm{C}$-isotherm reflect the meridional current systems off Portugal. Due to the lack of an appropriate $T-S$ relationship in the upwelling region of the continental shelf, the dynamic height east of $11^{\circ} \mathrm{W}$ may be questionable (we used extrapolated $T-S$ values). Nevertheless, we recognize, progressing from east to west, the southbound Portugal Current next to a counter current or eddy feature. A southward drift between $15^{\circ}$ and $21^{\circ} \mathrm{W}$ is reflected by the steep increase of the dynamic height around $22^{\circ} \mathrm{W}$. This signature is indicative of the meandering Azores Current being a persistent feature in that region (Käse et al., 1985; Siedler et al., 1985).

A real advantage of this system is that surveys can be carried out much more rapidly with this XBT system as the ship is continuously underway. The value of also being able to see the corresponding geopotential field
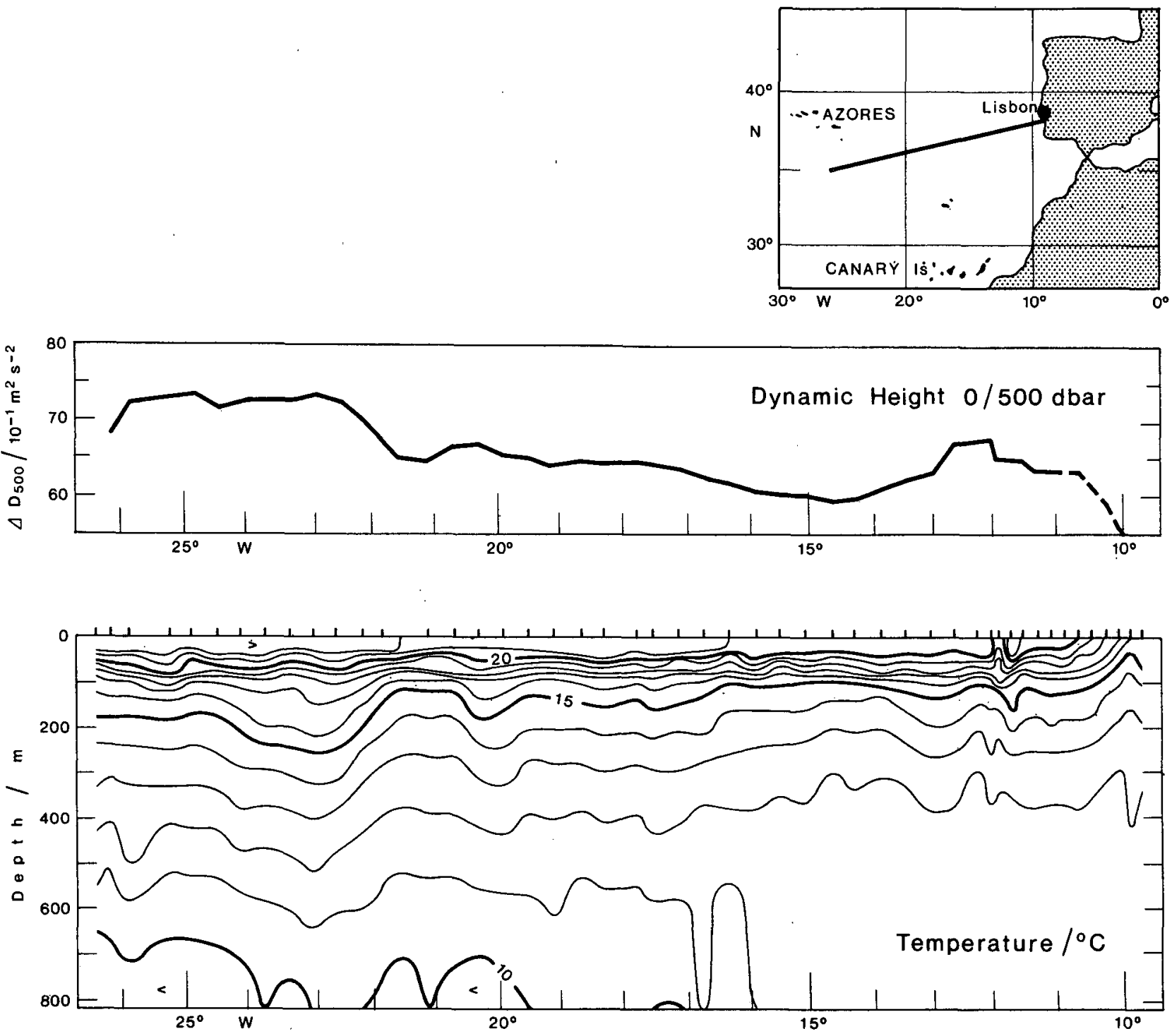

FIG. 4. Vertical XBT temperature section and horizontal 0/500 db dynamic height profile between Lisbon, Portugal and the Azores. 

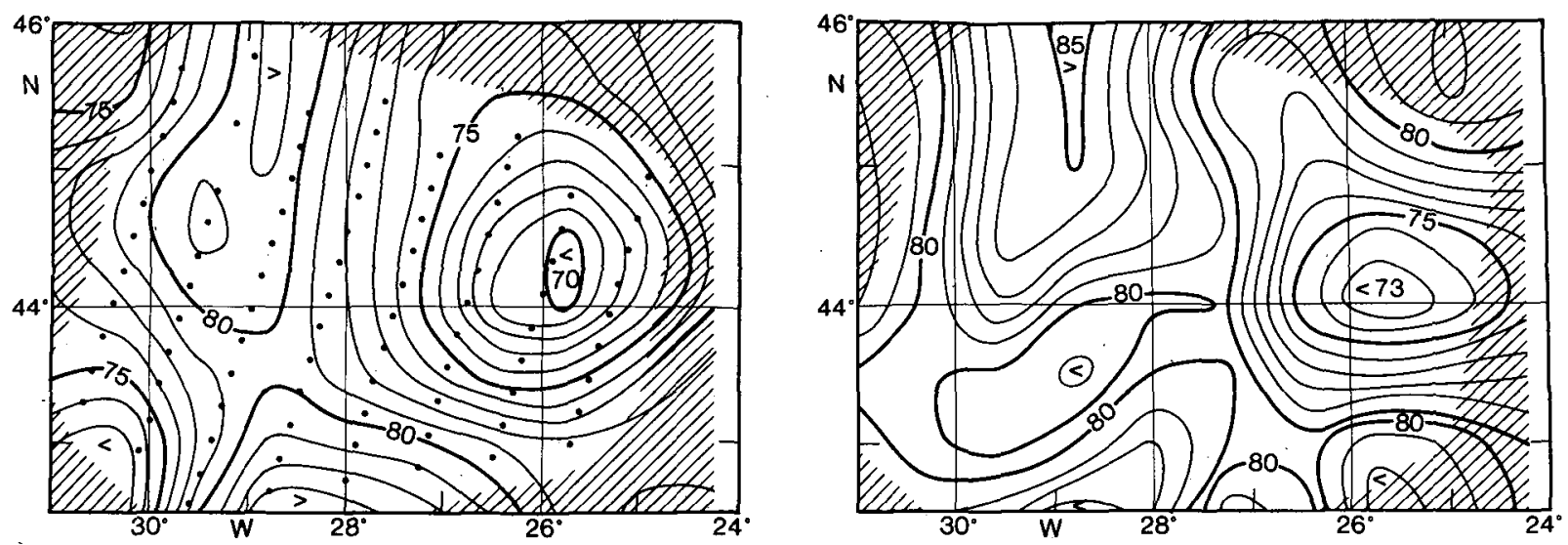

FIG. 5. Objectively analyzed dynamic topography (dyn $\mathrm{m}$ ) maps for XBT profiles (left) and CTD profiles (right). In each map the boundary shaded region indicates where the analysis error is greater than $2.5 \times 10^{-4}$.

in research vessel operations is that rapid surveys can help to dictate where more intensive measurements should be made.

As an example of how well such an XBT geopotential anomaly survey compares with one made using only the more accurate CTD casts we present the maps of Fig. 5. Here near simultaneous CTD and XBT casts were collected at each station within the survey. Using mean $T-S$ relationships the XBT data were provided with matching salinity profiles, converted to $50 / 800 \mathrm{db}$ dynamic heights and mapped using objective analysis (Hiller and Käse, 1983). Using the CTD data separately, similar 50/800 db geopotential anomaly maps were constructed with objective analysis. These two maps are plotted together in Fig. 5; here the dashed background lines indicate the region where the objective analysis error becomes significant and the maps are less reliable. The overall structure is common to both maps which demonstrates the utility of using the XBT data alone to survey the baroclinic structure. The main feature is the strong low in the central right portion of the survey. Both the spatial structure and the strength (geopotential difference) of this feature are well estimated by the XBT survey relative to the CTD map. Some differences are apparent in the lower left portion of the surveys which do affect the overall circulation pattern. Care must be taken here, however, where the boundary effects of the objective analysis procedure become important. Other comparisons, from this same geographic region (not shown here), demonstrate the correspondence between geopotential anomaly maps, based on XBT measurements, and the trajectories of satellite tracked drifting buoys (Krauss and Meincke, 1982).

\section{Summary}

A low-cost digital XBT system, based on a microcomputer, is described and the application of such a system to the real-time computation of geopotential anomaly is considered. Not only does such a digital system avoid the problems of time and error associated with the analog XBT systems but the low-cost of the system discussed makes it possible to install such equipment on a variety of ship-of-opportunity platforms for XBT data collection.

Acknowledgments. This system was originally developed at the Department of Oceanography, University of British Columbia. Thanks go to J. Wiggins who designed the circuit board and P. Nowlan who worked on the software. This early phase was supported by the U.S. Naval Ocean Research Development Agency (NORDA) Ocean Measurements Program (OMP) under Grant N0014-81-G-008; this support is gratefully acknowledged.

The system has been expanded and improved upon by many at the Institut fuer Meereskunde (IfM), Kiel, Germany. Hardware improvements were made by P. Meyer and U. Koy who also developed the "test box" unit. Also the data collection projects designed to test and evaluate the system.were supported as part of the Sonderforschungsbereich (SFB) 133 of the Deutsche Forschungsgemeinschaft (DFG), Bonn. In addition this paper was written during a sabbatical visit of WJE at IfM; Kiel supported by SFB 133. This support is also gratefully acknowledged. Thanks also go to $\mathrm{H}$. Hinricksen and $\mathrm{K}$. Janke who performed the error analyses.

\section{REFERENCES}

Emery, W. J., 1978: The errors involved in inferring salinity from sound velocity. J. Phys. Oceanogr., 7, 293-297.

- and A. O'Brien, 1978: Inferring salinity from temperature or depth for dynamic height computations in the North Pacific. Atmos. Ocean, 16, 318-366.

- and L. S. Dewar, 1982: Mean temperature-salinity, salinitydepth and temperature-depth curves in the North Atlantic and North Pacific. Progress in Oceanography, Vol. 3, Pergamon, 91 pp. 
Flierl, G. R., 1978: Correcting expendable bathythermograph (XBT) data for salinity effects to compute dynamic heights in Gulf Stream Rings. Deep-Sea Res., 25, 129-134.

Heinmiller, R. H., C. C. Ebbesmeyer, B. A. Taft, D. B. Olson and O. P. Niktin, 1983: Systematic errors in expendable bathythermograph (XBT) profiles. Deep-Sea Res., 30, 1185-1197.

Hiller, W., and R. H. Käse, 1983: Objective analysis of hydrographic data sets from mesoscale surveys. Rep. IfM Kiel, No. 116, 78 pp.

Joyce, T., J. Dean, M. McCartney, R. Millard, D. Moller, A. Voorhis, C. Dahm, D. Georgi, G. Kullenberg, J. Toole and W. Zenk, 1976: Observations of the Antarctic Polar Front during FDRAKE 76: A cruise report, WHOI-76-74, Woods Hole, MA, $150 \mathrm{pp}$.

Käse, R., W. Zenk, T. B. Sanford and W. Hiller, 1985: Currents, fronts and eddy fluxes in the Canary Basin. Progress in Oceanography, Vol. 14, Pergamon, 231-257.

Krauss, W., and J. Meincke, 1982: Drifting buoy trajectories in the North Atlantic Current. Nature, 296, 737-710.

Mesacar, R., and J. Wagner, 1980: Applications of a data-compression algorithm for XBT bathy-message preparation. Proc. of Near
Surface Ocean Experimental Technology Workshop, NORDA, NSTL Station, MI, 139-147.

Montgomery, R. B., and W. S. Wooster, 1954: Thermosteric anomaly and the analysis of serial oceanographic data. Deep-Sea Res., 2 , 63-70.

Siedler, G., and L. Stramma, 1983: The applicability of the $t / S$ method to geopotential anomaly computations in the North-East Atlantic. Oceanol. Acta, 6, 167-172.

- W. Zenk and W. Emery. 1985: Strong current events related to a subtropical front in the Northeast Atlantic. J. Phys. Oceanogr., 15, 885-897.

Sippican (1970): Ocean Engineering Bull. No. 1.

Steinhart, J. S., and S. R. Hart, 1968: Calibration curves for thermistors. Deep-Sea Res., 15, 497-503.

Sverdrup, H. U., M. W. Johnson and R. H. Fleming, 1942: The Oceans.

Zantopp, R. J., and K. D. Leaman, 1984: The feasibility of dynamic height determination from moored temperature sensors. J. Phys. Oceanogr., 8, 1399-1406.

Zenk, W., and Co-workers, 1985: The XBT digital data acquisition system of Kiel University-Tech. Rep. Berichte aus dem Institut für Meereskunde (in preparation). 